\title{
Physical and Mechanical Characterization of Artificial Stone with Marble Calcite Waste and Epoxy Resin
}

\author{
Fernanda Souza Silva ${ }^{a, b *}$, Carlos Eduardo Gomes Ribeiro ${ }^{b}$, Rubén Jesus Sánchez Rodriguez ${ }^{a}$ \\ ${ }^{a}$ Laboratório de Materiais Avançados, Setor de Polímeros, Universidade Estadual do Norte Fluminense \\ Darcy Ribeiro - UENF, Av. Alberto Lamego, 2000, Campos dos Goytacazes, RJ, Brazil \\ ${ }^{b}$ Setor de Engenharia Mecânica, Instituto Federal do Espirito Santo - IFES, Campus Cachoeiro de \\ Itapemirim, Rodovia Cachoeiro x Alegre, Km 5, Morro Grande, Cachoeiro de Itapemirim, ES, Brazil
}

Received: July 06, 2017; Revised: October 17, 2017; Accepted: November 10, 2017

\begin{abstract}
The incorporation of calcite marble waste in epoxy resin for the production of artificial stone can represent a technical-economical method and environmentally viable, reducing the amount of discarded residue in the environment, and adding economic value to marble waste and enabling the generation of jobs. The production of natural stone in Brazil recorded an exorbitant amount of waste generated in marble processing. Only $75 \%$ of marble taken from the deposits it becomes the finished product the rest is discarded. This study aimed to evaluate the mechanical and physical properties of produced artificial marble based in calcite marble waste and epoxy resin. The vacuum vibro compression was used for production as artificial marble and the specimens were cut according to standart NBR 15845. The results indicated that the artificial stones exhibit physical and mechanical results within the expected range for these kinds of materials. Artificial marble with a maximum flexural strength of 31,8 MPa, maximum compressive strength of $85,2 \mathrm{MPa}$, water absorption below $0.05 \%$ and a satisfactory adhesion between load and resin were obtained for the materials produced with $80 \% \mathrm{wt}$ marble particles and 20\% wt epoxy resin, enabling the development of an alternative material for civil construction applications.
\end{abstract}

Keywords: Artificial marble, properties mechanical, calcite.

\section{Introduction}

In recent years, the extraction of natural stone such as marble and granite presented a significant increase. This increase was mainly due to the use of these materials in works in construction and also for export. The Brazilian production of these materials during the year 2013, according to Abirochas, achieved a new record of 10.5 million tons ${ }^{1}$. In marble extraction and sawing of blocks, a significant volume of waste is generated, requiring larger spaces to deposit every day ${ }^{2}$. Today, Brazil is the fourth largest producer of ornamental stones in the world with a total production of 9.3 million tons in $2016^{3}$.

The data from the production of natural stone in Brazil recorded an exorbitant amount of waste generated in marble processing. Only $75 \%$ of marble taken from the deposits it becomes the finished product the rest is discarded as waste $^{2}$. According to the information Abirochas 01/2015 , $^{4}$ the Brazilian mining production during the year 2014 was estimated at 10.13 million tonnes, of which $64 \%$ allocated to the Southeast. There is an approximate $25 \%$ loss of the marble removed as waste. The advantage of this study, on the other hand, is that by-products of marble powder have priceless because waste is recycled ${ }^{5}$.

*e-mail: tecnicananda@gmail.com
In this context, to meet the requirements imposed for environmental laws, emerged new developments in materials, generating products known as artificial stones, produced with stone wastes and polymeric resin ${ }^{4,6}$. Epoxy resins are a good example of advancement in the development of composite materials and are one of the most important classes of thermosetting polymers because they offer an excellent combination of unattainable properties in other thermosetting resins ${ }^{7}$.

Artificial stones has demonstrated a high market value and also an increasing demand in recent times ${ }^{4}$. Typically named as stone industrialized consists of 95\% natural aggregates, that is, substantially a natural material. The aggregates that form artificial stone may be composed of- pieces of marble, crushed granite, quartz sand, glass crystals, and other components - that are aggregated with bonds agents such as epoxy resin ${ }^{8}$. Several studies have shown that size of the particles influence the mechanical properties. Usually attributed to the fine particle size distribution of the waste marble-by-product ${ }^{9}$.

Renowned companies claim that the artificial marble has considerable qualities, which justifies the good acceptance in the consumer market. Among the advantages artificial stones are solid, impermeable, good mechanic resistant and had liquid penetration resistant, remaining only on the 
surface. This is caused by resin used in the manufacturing process, that provide adhesion between the stone particles and also penetrate between the interstices, eliminating the porosity of natural stones ${ }^{6,10}$.

Several producers said about advantages of artificial stones. As comparative technical characteristics of the natural stones with artificial stones, Caesarstone ${ }^{6}$ exhibits properties of artificial stones, such as flexural strength results having a superiority to natural calcite marbles of approximately $600 \%$; yet for the compressive strength values, a superior $400 \%$ of the raw material (marble calcite); and only $0.02 \%$ as the percentage of water absorption.

Brazil, despite being one of the world's largest producers of natural ornamental rocks, still does not stand out when it comes to artificial rocks. A reflection of this is the large volume of artificial rocks imported annually ${ }^{11}$. Related to economic values, according with Abirochas ${ }^{4} 12 / 2014$, imports of artificial stones remained near to those of natural materials and, unlike them, had a significant increase in physical volume $(+31.42 \%)$. Artificial stones showed imports of USD 43.9 million and 48.1 thousand tons in September of 2014. Its average price (USD 890.8/t) also remains higher than that of natural materials also imported (USD 705 8/t).

Thus, recycling and reuse of ornamental stone wastes for the development of artificial stones, can be technicaleconomic and environmentally viable, minimizing the amount of wastes disposed in environment, while incorporating economic value to residue and be able to create new jobs ${ }^{12}$. The marble particles obtained from can be reused instead of being deposited in the environment ${ }^{13}$.

\section{Material and Methods}

The waste of calcite marble was used in this study, from Polita company, in Cachoeiro de Itapemirim, ES, Brazil, and as resin, it was used an epoxy resin diglycidyl ether of bisphenol A (DGEBA), supplied by Dow Chemical A/S; trade name: DER 331; density: 1,16 g/ml and molar mass: 340,41 g/mol. In addition, as hardener was used Tetraethylenepentamine amine (TEPA), supplied by Sigma Aldrich; density: $0.99 \mathrm{~g} /$ $\mathrm{ml}$ and molecular weight: 189.31 .

The marble waste were classified among the sieves 10 and 200 mesh and divided into three different particle sizes. The larger particles (coarse) was classified in the range of $2 \mathrm{~mm}$ to $0,42 \mathrm{~mm}$, the medium particles were comprised between $0,42 \mathrm{~mm}$ up to $0.075 \mathrm{~mm}$, and fine particles were less than $0.075 \mathrm{~mm}$. The ratio of each particle size was based on the study by Ribeiro ${ }^{12}$, that investigated higher packings for calcite marble particles, seeking to increase properties of produced materials, because this composition was based on a study seeking better density and greater homogeneity, through in study of Ribeiro ${ }^{12}$ that used a model mathematical -"simplex" to provide the most composition with better packing of waste marble.

\subsection{Production of artificial marble slabs}

The artificial marble slabs were produced in dimensions $200 \times 200 \times 10 \mathrm{~mm}$ through a vaccum vibro compression equipment developed for this line of research.

\subsection{Characterization of artificial marble slabs}

For the slabs of artificial stones were evaluated the physical and mechanical properties by standard tests such as density, water absorption, porosity, compressive strength, flexural strength, impact, abrasive wear, dynamic mechanical analysis, thermogravimetric analysis and scanning electron microscopy.

The determination of density, water absorption and apparent porosity was based in Annex B from ABNT NBR 15845 , using 11 cubic samples, with dimensions ( $30 \times 30$ x 30) $\mathrm{mm}$.

The compressive strength test was conducted in EMIC universal machine tests, model DL10000, based in appendix E from ABNT NBR 15845, using 10 dried cubic samples with dimensions $30 \times 30 \times 30 \mathrm{~mm}$.

The flexural strength test at three points was conducted in EMIC universal machine tests, model DL10000, based in appendix F from ABNT NBR 15845, using 6 samples with dimensions $10 \times 25 \times 100 \mathrm{~mm}$.

The abrasion test was conducted in AMSLER abrasive test equipment, based from NBR 12042, using two samples with dimensions $70 \times 70 \times 30 \mathrm{~mm}$.

The impact test the hard body was based in appendix $\mathrm{H}$ from ABNT NBR 15845, using three samples with dimensions $10 \times 200 \times 200 \mathrm{~mm}$.

For the thermal test was conducted the thermogravimetry with equipament TGA-Q5000 TA Instruments. Thermogravimetric analysis was performed in a temperature range from $30^{\circ} \mathrm{C}$ to $1000^{\circ} \mathrm{C}$ at a heating rate of $10^{\circ} \mathrm{C} / \mathrm{min}$ using an air flow of $60 \mathrm{ml} / \mathrm{min}$ during testing.

The dynamic mechanical analysis was conducted on the thermal characterization unit DMA Q800 TA Instruments in a frequency of $1 \mathrm{~Hz}$, amplitude $20 \mu \mathrm{m}$, static force of 0.1 $\mathrm{N}$ and a heating rate of $3{ }^{\circ} \mathrm{C} / \mathrm{min}$.

Scanning electron microscopy (SEM) analysis of gold sputtered fractured specimens, was conducted in a model Super Scan SSX-550 da SHIMADZU.

\section{Results}

\subsection{Properties of Artificial Stone}

\subsubsection{Physical properties}

The results are presented as average \pm standard error.

The average apparent density obtained of the produced artificial marble was $2.23 \pm 0.02 \mathrm{~g} / \mathrm{cm}^{3}$ that is $8 \%$ lower than those reported for the compound marble manufacturers that 
inform density values between 2.4 and $2.5 \mathrm{~g} / \mathrm{cm}^{3}$. Lee et al. ${ }^{16}$ in his research of artificial stone has diversified compression level, pressure levels, vacuum level and vibration frequency in the production process and so found values ranging from 2.03 to $2.45 \mathrm{~g} / \mathrm{cm}^{3}$. Ribeiro et al. ${ }^{14}$ using the same load of calcitic marble and polyester resin, obtained the value of from $2.27 \mathrm{~g} / \mathrm{cm}^{3}$. The density value found in this research is in agreement with the literature, with no significant changes in results.

With respect to water absorption value of artificial marble produced was found of $0.05 \pm 0.01 \%$. This value is $45 \%$ below the minimum expected for the industrialized artificial marble. This is because the values reported by artificial marble manufacturers are in the range from 0.09 to $0.40 \%{ }^{9}$. According to Chiodi and Rodriguez ${ }^{16}$, a value below $0.1 \%$ has a very high quality. This low absorption found in the production of artificial marbles occurred due to the efficient wetting of the load by the resin, providing a good interface in the material produced.

The value found for water absorption is also lower than recommended for calcite marble (material regulated by ASTM C503) should have the least absorption of from to $0.20 \%{ }^{17}$. Lee et al..$^{17}$ changing the production variables has found values from 0.01 to $0.20 \%$. Borsellino et al. ${ }^{18}$ using residues marble and epoxy resin in open mold, obtained the value of $0.25 \%$. Since compared with Ribeiro et al. ${ }^{14}$, it reported an average of $0.19 \pm 0.02 \%$. Whereas that this used the same calcitic marble load and only varied the resin since it used the polyester resin it is inferred that low water absorption and porosity level found in this study indicate a good compacting and distribution of calcite residue in epoxy resin matrix used. For the apparent porosity was found a mean value of $0.11 \pm 0.03 \%$ showing excellent physical properties of the formulated artificial marble. Chiodi and Rodrigue $z^{16}$ said that high quality materials must have porosity below $0.5 \%$. The low porosity was due to the good adhesion of the resin to the marble load and also because the resin occupied the voids, providing homogeneity to the system.

\subsubsection{Mechanical properties}

In the bending flexural strength test at three points it was obtained the value of $31.87 \pm 2,58 \mathrm{MPa}$ greater than the minimum expected for calcite marble regulated by ASTM C503 that should be greater than $7 \mathrm{MPa}$. The result indicates a low dispersion results and a considerable mechanical stability of the artificial material produced. Note that identified a considerable increase in the mechanical properties when compared to natural marbles, due to the inference that the degree of molecular interconnections efficiently occurred between the matrix and the load. Table 1 exhibited the Flexural strength values for the artificial marble produced.

Ribeiro et al. ${ }^{14}$ obtained value of $21.5 \pm 1,9 \mathrm{MPa}$ for artificial stone produced with marble residues, polyester resin and a solvent, probably because Ribeiro et al. ${ }^{14}$ used the
Table 1. Flexural strength values for the artificial marble produced.

\begin{tabular}{cc}
\hline Material & Flexural strenght (MPa) \\
\hline CP 01 & 30,50 \\
CP 02 & 37,42 \\
CP 03 & 33,49 \\
CP 04 & 30,68 \\
CP 05 & 31,49 \\
CP 06 & 32,25 \\
\hline
\end{tabular}

solvent that decreased the strength of the chemical bonds of the final product. Other manufacturers of stone industrialized marble base reported values contained within the range of 13.6 to $17,2 \mathrm{MPa}$. Borsellino et al. ${ }^{18}$ was used marble residues and epoxy resin and obtained results as flexural strength values of 10.6 and $22,2 \mathrm{MPa}$, that is, the result obtained in this study is $43.5 \%$ above the expected results according to the manufacturers commercials. Borsellino et al..$^{18}$ however did not use the vacuum method for the production of artificial plates which justifies lower flexural values. It was that the faults of the vacuum provides a more porous material that act as stress concentrators.

In compressive strength test it was found $85.20 \pm 7,8$ $\mathrm{MPa}$ and as elastic modulus was obtained value of $2.05 \pm$ $0,28 \mathrm{GPa}$. The lowest values obtained to calcite marble to compressive strength demonstrated that such material was more easier have mobility of crystal planes at the time of efforts of compressive strength, feature occurring from the imperfections of its particles a fact that has been reduced in the production of artificial stone.

Although there are no a specific standard for compressive strenght rating for artificial stone, Chiodi and Rodriguez ${ }^{16}$ reported that for ornamental flooring the amounts classified between 70 and $130 \mathrm{MPa}$ have satisfactory compressive strenght classification. Table 2 shows the Compressive strength values for the artificial stone produced.

There is no standard to present limits to abrasive wear. Chiodi Filho and Rodriguez ${ }^{16}$ had published paper presenting technological parameters for the use of ornamental stones in the flooring. These authors say that for high traffic floors, the wear must be less than $1.5 \mathrm{~mm}$ for average traffic should be less than $3 \mathrm{~mm}$ and to down traffic wear should be smaller than $6 \mathrm{~mm}$. Thus, following the described technological parameters, the produced artificial stone can be used for high traffic floors due to low wear presented, below $1.5 \mathrm{~mm}$ on the track $1000 \mathrm{~m}$.

In the result of resistance to hard body impact, it was noted that the artificial stone produced showed cracks happen from a height of $0.43 \mathrm{~m}$. This amount was obtained by averaging the results of the test samples. It is considered that value as positive, since according to the study Frazão and Farjallat ${ }^{19}$, the optimal values for granite must be greater than or equal to $0.4 \mathrm{~m}$. Note that the granite characterized by these authors has superior strength the calcite marble used in this work. 
Table 2. Compressive strength values for the artificial stone produced.

\begin{tabular}{cc}
\hline Material & Compressive strenght (MPa) \\
\hline CP 01 & 95,89 \\
CP 02 & 91,29 \\
CP 03 & 89,36 \\
CP 04 & 69,39 \\
CP 05 & 88,77 \\
CP 06 & 90,40 \\
CP 07 & 78,90 \\
CP 08 & 84,16 \\
CP 09 & 76,68 \\
CP 10 & 81,96 \\
CP 11 & 90,39 \\
\hline
\end{tabular}

Figure 1 shows the results of Mechanical test dynamic for the resin, artificial stone and natural marble.

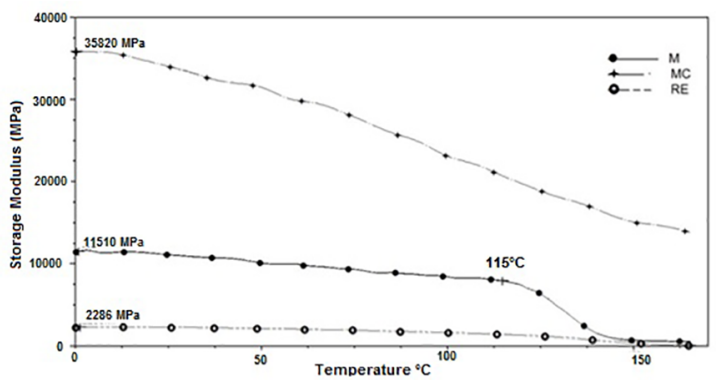

Figure 1. Mechanical test dynamic.

Ribeiro and Rodrigue ${ }^{20}$ also made mechanical dynamic tests on artificial stones produced the base of calcite marble and polyester resin. For calcite marble the behavior was the same that was identified in this study. That is a fragile behavior is known for these naturals materials. As for the artificial material it identified a material with elastic-plastic behavior and the moment elastic at the beginning of the test and after reaching the yield point the plastic behavior predominated in this moment.

Identified that the artificial stone produced shows storage modulus greater than the epoxy system across the temperature range used in the mechanical test dinamic. Note also that the module found for the artificial stone is located between its constituents, as expected for a mixture. In the artificial stone produced, the movement of the molecular network is reduced by the presence of load. The Tg was value recorded near $140{ }^{\circ} \mathrm{C}$, indicating that the artificial material is in the glassy state ambient temperature.

Through dynamic mechanical testing was conducted a comparative study of the natural marble and artificial stone. Is observed for the artificial stone an elastic behavior at temperatures below $120{ }^{\circ} \mathrm{C}$ with a storage modulus near $12000 \mathrm{MPa}$ practically constant until the glass transition temperature of the aggregating agent of calcite particles, the resin DEGBA-TEPA.

The natural marble calcite (MC) has a much bigger storage module $36000 \mathrm{MPa}$ showing a progressive decrease with increasing temperature probably associated with the porous structure of this material and keeping your elastic properties throughout the temperature range of the object of study.

\subsubsection{Thermogravimetric and Microscopic Properties}

The graph of the test of thermogravimetry is showed in Figure 2.

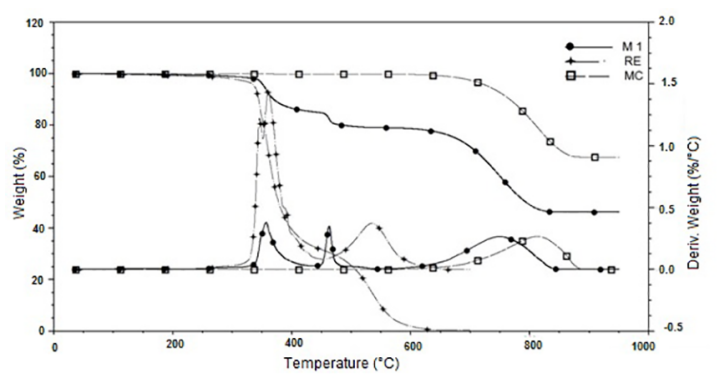

Figure 2. Thermogravimetry.

The curve of calcite marble has a mass loss around $45 \%$ of the total weight at approximate temperature of $830^{\circ} \mathrm{C}$ due to the decomposition of the carbonate to oxide. The behavior observed for calcite marble in this study follows the same behavior observed by Souza and Bragança ${ }^{15}$ that observed to calcite was observed a loss of approximately $43 \%$ by weight around $850{ }^{\circ} \mathrm{C}$. Barcina et al. ${ }^{16}$ also observed similar profile to calcareous, observing a loss of about $44 \%$ by weight in the approximate temperature of $800^{\circ} \mathrm{C}$. Ribeiro and Rodrigue ${ }^{20}$ also conducted a survey of natural calcite marble and obtained $44 \%$ of weight loss in about $850^{\circ} \mathrm{C}$.

The curve representing the epoxy resin registering a first mass loss of about $70 \%$ by weight at temperature of about $380^{\circ} \mathrm{C}$ due to decomposition of the resin. Already at about $550{ }^{\circ} \mathrm{C}$, the resin showed a decrease in mass around $90 \%$ of the mass due to combustion of the remaining breeze of the epoxy resin under high temperature.

The first stage of thermogravimetric curve of the artificial stone produced shows a weight loss of approximately $20 \%$ at the temperature of about $480{ }^{\circ} \mathrm{C}$ concerning the decomposition of the resin. The second phase, between about 680 and 800 ${ }^{\circ} \mathrm{C}$, shows a loss of mass around $45 \%$ of the total weight due to decomposition of the carbonate to oxide.

There were no found evident pores showing that the fracture may have occurred through pores or fault of adesion among the resin and the load that may have acted as stress concentrators. The fracture surfaces showed surfaces intragranular fractures with mechanical disruption due to mechanical stress, as well as particles adhered to resin, demonstrating the effective interfacial adhesion in the materials, this fact was showed in Figure 3. 

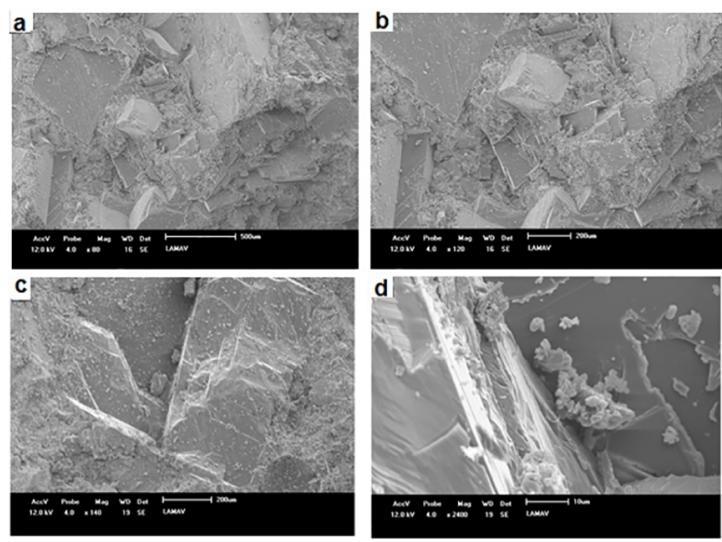

Figure 3. (a, b, c, d) Scanning electron micrographs of fracture surfaces of the artificial marble produced increases with 80x (a), 120x (b), 140x (c) and 2400x (d).

Increasing the resin phase improves the load on the resin adhesion and can reduce the loss factor in the formulations due to the reduced friction between the polymer and the calcitic particles in the interface ${ }^{23}$.

It was also produced a stone artificial in proportion of $80 \% \mathrm{wt} / \mathrm{tw}$ of residues without the action of vacuum and compaction, that lower values of flexural strength of 28.8 MPa were obtained. In the same proportion of $80 \%$ calcitic residue under vacuum and compression (vibro compression methodology), a mean flexural strength of 31.8 MPa was obtained, showing the influence of these process variables on the mechanical properties, generating results with growth rates of $10 \%$ in the flexural strength only by varying these parameters due to the porosity which act as tensions concentrators.

Figure 4 (a, b, c, d) represent SEM (scanning electron microscopy) micrographs of the fracture surface of the artificial marble produced in the proportion of $60 \% \mathrm{wt} /$ wt residue without vacuum action and compression in the formulation process.
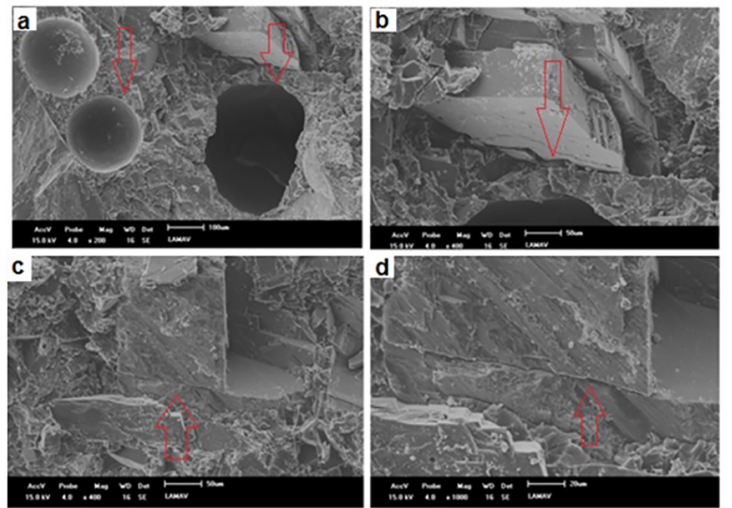

Figure 4. Scanning electron micrograph of the fracture region of the artificial marble with $60 \% \mathrm{wt} / \mathrm{wt}$ of residue without vacuum action and compaction with increases of 200x (a), 400x (b), 400x (c), 1000x (d) and 2000x (e).
Cavity and heterogeneity (according to blank-redarrow in the micrographs showed in the Figure 4) are more pronounced than in the formulation of higher residue content. The presence of cavities / pores due to fault of vacuum action and inefficient wetting resulted in unsatisfactory adhesion of the resin and load. Particles in contact without the presence of the interface with the resin are observed as well as the presence of voids which may have acted as stress concentrators, resulting in lower mechanical properties as recorded in the three-point flexural tests.

\section{Conclusions}

The use of this epoxy resin together with the load of calcite generates a high-performance product with excellent properties, providing both environmental solutions for waste as benefits economics. The artificial marble produced can have a wide range of use, either in residential or commercial spaces. The use of this type of material provides style, elegance and constant innovation. In addition, artificial marble presents advantages over natural rocks, such as low porosity, low water absorption and considerable mechanical properties.

It was observed the flexural strength value for the artificial marble produced was $31.87 \mathrm{MPa}$, and has for compression was $85.20 \mathrm{MPa}$, such mechanical values are satisfactory. The physical results are also excellent porosity of only $0.11 \%$ and $0.05 \%$ of absorption, demonstrating the high impermeability and quality of the artificial material produced.

In the hard body test, the artificial stone had fails from a height of $0.43 \mathrm{~m}$, good value for this type of artificial material. For abrasive wear of Amsler type testing, interesting results were also obtained inferred that the produced artificial marble can be used for high traffic floors due to low wear presented, below $1.5 \mathrm{~mm}$ in track $1000 \mathrm{~m}$.

The results indicated thermogravimetric mass loss behavior as expected for artificial stones, epoxy system DGEBA / TEPA and natural calcitic stone. For the artificial marble was a decomposition of $\mathrm{CaCO}_{3}$ into oxides.

The use of vibro vacuum compression allowed a better interface and adhesion of the load in the epoxy matrix, with lower porosity, providing better mechanical properties for the produced artificial marble. The Scanning electron micrographs of fracture indicated that calcite load had excellent adhesion to epoxy matrix DGEBA / TEPA, not being visible pores that may have acted as stress concentrators.

\section{Acknowledgements}

The authors thank CETEM by tests of hard body impact and abrasive wear.

\section{References}

1. Montani C. Dossiê Brasil 2014. Brasília: Aldus; 2014. 
2. Souza LR, Ribeiro RCC, Carrisso RCC, Silva LP, Pacheco EBAV, Visconte LLY. Aplicação de Resíduos de Mármore na Indústria Polimérica. Série Tecnologia Ambiental. Rio de Janeiro: CETEM/MCT; 2009. 36 p.

3. ABIROCHAS. Balanço das Exportações e Importações Brasileiras de Rochas Ornamentais em 2016. Brasília: ABIROCHAS; 2017. Available from: <http://www.ivolution. com.br/mais/fotos/6/17/4062/Informe_01_2017.pdf $>$. Access in: $17 / 05 / 2017$.

4. ABIROCHAS. Balanço das Exportações, Importações, Produção e Consumo Interno Brasileiro de Rochas Ornamentais em 2014. São Paulo: ABIROCHAS; 2015. Available from: $<$ http://www. ivolution.com.br/mais/fotos/6/17/3397/Informe_01_2015.pdf $>$. Access in: 22/01/2015.

5. Kirgiz MS. Use of ultrafine marble and brick particles as alternative raw materials for clinkerization. ZKG International. 2014;4:36-44

6. Caesarstone. CaesarStone Quartz Surfaces. Available from: $<$ http://www.caesarstoneus.com/catalog/technical-specs.cfm $>$. Access in: 01/03/2014.

7. Roşu D, Caşcaval CN, Mustała F, Ciobanu C. Cure kinetics of epoxy resins studied by non-isothermal DSC data. Thermochimica Acta. 2002;383(1-2):119-127.

8. Pedra Artificial. O que é Pedra Artificial?. Available from: $<$ www.pedraartificial.com.br>. Access in: 02/05/2014.

9. Kirgiz MS. Strength gain mechanisms of blended-cements containing marble powder and brick powder. KSCE Journal of Civil Engineering. 2015;19(1):165-172.

10. Breton Company. Plants for Manufacturing Natural Stone Surfaces by Breton Technology. Available from: $<$ http://www. breton.it/dynamic/en/azienda/filosofia.php?PHPSESSID $=758$ 9075f46902f6787a285ee1fd4a116>. Access in: 01/03/2014.

11. ABIROCHAS. Balanço das exportações e importações brasileiras de rochas ornamentais em 2015. Brasília: ABIROCHAS; 2016. Available from: <http://www.ivolution.com.br/mais/ fotos/6/17/3609/Informe_01_2016.pdf $>$. Access in: 22/05/2016.

12. Ribeiro CEG, Rodriguez RJS, Vieira CMF. Determination of Apparent Dry Density for Ternary Mixture of Crushed Marble Waste. In: Yurko J, Zhang L, Allanore A, Wang C, Spangenberger JS, Kirchain RE, et al., eds. EPD Congress 2014. Hoboken: John Wiley \& Sons; 2014. p. 83-89.
13. Kirgiz MS. Use of ultrafine marble and brick particles as raw materials in cement manufacturing. Materials and Structures. 2015;48(9):2929-2941.

14. Ribeiro CEG, Rodriguez RJS, Vieira CMF. Production of Ornamental Compound Marble with Marble Waste and Unsaturated Polyester. In: Yurko J, Zhang L, Allanore A, Wang C, Spangenberger JS, Kirchain RE, et al., eds. EPD Congress 2014. Hoboken: John Wiley \& Sons; 2014. p. 129-136.

15. Aglostone. O qué éo Aglostone?. Available from: $<\mathrm{http}: / / \mathrm{www}$. aglostone.com.br/>. Access in: 17/06/2015.

16. Chiodi Filho C, Rodrigues EdeP. Guia de aplicação de rochas em revestimentos. São Paulo: ABIROCHAS; 2009. 118 p.

17. Lee MY, Ko CH, Chang FC, Lo SL, Lin JD, Shan MY, et al. Artificial stone slab production using waste glass, stone fragments and vacuum vibratory compaction. Cement and Concrete Composites. 2008;30(7):583-587.

18. Borsellino C, Calabrese L, Di Bella G. Effects of powder concentration and type of resin on the performance of marble composite structures. Construction and Building Materials. 2009;23(5):1915-1921.

19. Frazão EB, Farjallat JES. Características tecnológicas das principais rochas silicáticas brasileiras usadas como pedras de revestimento. I Congresso Internacional da Pedra Natural; 1995; Lisbon, Portugal. p. 47-58.

20. Ribeiro CEG, Rodriguez RJS. Influence of Compaction Pressure and Particle Content on Thermal and Mechanical Behavior of Artificial Marbles with Marble Waste and Unsaturated Polyester. Materials Research. 2015;18(Suppl 2):283-290. DOI: $10.1590 / 1516-1439.372314$

21. Souza F, Bragança SR. Thermogravimetric analysis of limestones with different contents of $\mathrm{MgO}$ and microstructural characterization in oxy-combustion. Thermochimica Acta. 2013;561:19-25. DOI: 10.1016/j.tca.2013.03.006

22. Barcina LM, Espina A, Suárez M, García JR, Rodríguez J. Characterization of monumental carbonate stones by thermal analysis (TG, DTG and DSC). Thermochimica Acta. 1997;290(2):181-189. DOI: 10.1016/S0040-6031(96)03074-2

23. Kubát J, Rigdahl M, Welander M. Characterization of interfacial interactions in high density polyethylene filled with glass spheres using dynamic-mechanical analysis. Journal of Applied Polymer Science. 1990;39(7):1527-1539. 